\title{
ITP Filter Particulate Decontamination Measurement
}

by

L. O. Dworjanyn

Westinghouse Savannah River Company

Savannah River Site

Aiken, South Carolina 29808

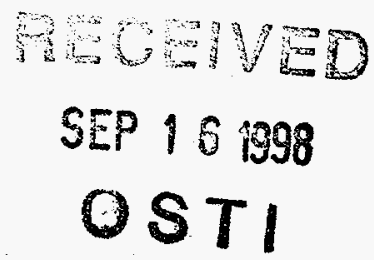

DOE Contract No. DE-AC09-89SR18035

This paper was prepared in connection with work done under the above contract number with the U.S. Department of Energy. By acceptance of this paper, the publisher and/or recipient acknowledges the U.S. Government's right to retain a nonexclusive, royalty-free license in and to any copyright covering this paper, along with the right to reproduce and to authorize others to reproduce all or part of the copyrighted paper.

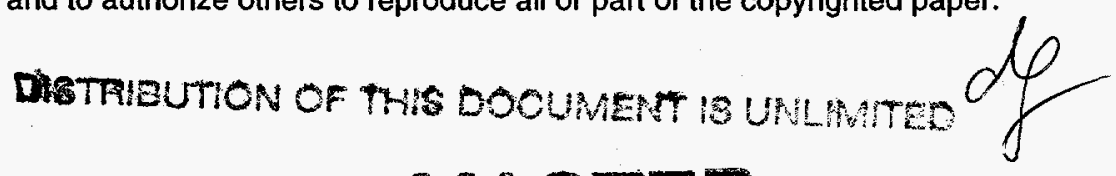




\section{DISCLAIMER}

This report was prepared as an account of work sponsored by an agency of the United States Government. Neither the United States Government nor any agency thereof, nor any of their employees, makes any warranty, express or implied, or assumes any legal liability or responsibility for the accuracy, completeness, or usefulness of any information, apparatus, product, or process disclosed, or represents that its use would not infringe privately owned rights. Reference herein to any specific commercial product, process, or service by trade name, trademark, manufacturer, or otherwise does not necessarily constitute or imply its endorsement, recommendation, or favoring by the United States Government or any agency thereof. The views and opinions of authors expressed herein do not necessarily state or reflect those of the United States Government or any agency thereof.

This report has been reproduced directly from the best available copy.

Available to DOE and DOE contractors from the Office of Scientific and Technical Information, P. O. Box 62, Oak Ridge, TN 37831; prices available from (423) 576-8401.

Available to the public from the National Technical Information Service, U. S. Department of Commerce, 5285 Port Royal Road, Springfield, VA 22161. 


\section{DISCLAIMER}

Portions of this document may be illegible in electronic image products. Images are produced from the best available original document. 


\section{4}

WESTINGHOUSE SAVANNAH RIVER COMPANY SAVANNAH RIVER TECHNOLOGY CENTER
WSRC-RP $-93-768$
K. Hofetettor L.Kilpotrich

c. Leangng 9. Wood Toded wright Bob. Holen R. Qunp? Q. Morin Q. E. Marra R. lawe.

Keywords :

Decontamination

Filtration

Crossflow

ITP

Cesium

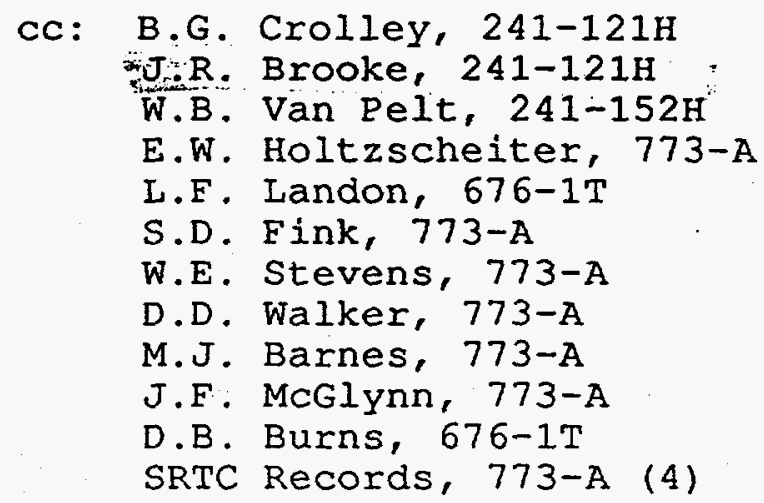

TO: W.L. TAMOSAITIS, 773-A

FROM: L.O. DWORJANYN, 779-2A LeOtwryangr

ITP FIITER PARTICUTATE DECONTAMINATION MEASUREMENT (U)

\section{SUMMARY}

A new test method was developed which showed the installed In-Tank Precipitation Filter Unit \#3 provided at least 40,000x decontamination of the precipitated potassium tetraphenyl borate (KTPB) during the cold chemical runs. This filter is expected to meet the needed $40,000 \times$ hot cesium decontamination requirements, assuming that the cesium precipitate, CSTPB, behaves the same as KTPB .

The new method permits cold chemicals field testing of installed filters to quantify particulate decontamination and verify filter integrity before going hot. The method involves a $1000 \mathrm{x}$ 
WSRC-RP-93-768

Page 2

May 21, 1993

concentration of fine particulate KTPB in the filtrate to allow direct analysis by counting for naturally radioactive isotope $\mathrm{K}-40$ using the underground SRTC gamma spectroscopy facility. The particulate concentration was accomplished by ultra filtration at Rhone-Poulenc, $N J$, using a small cross-flow bench facility, followed by collection of all suspended solids on a small filter disc for $K$ analysis.

\section{INTRODUCTION}

The main function for In Tank Precipitation (ITP) filters is the removal of fine precipitated cesium tetraphenyl borate. Earlier. demonstration in Tank 48 has shown that the filtered salt solution can be decontaminated from cesium by a factor of 40,000 (Ref. 1 ). This permits local salt disposal as a Class A saltcrete. The decontamination factor (DF) is a function of CSTPB solubility and removal of precipitated CsTPB. The solubility of cesium salt in ITP sodium salt solutions has been established (Ref. 2), as shown

$$
\mathrm{CSTPB}=0.000032 \exp (-0.67[\mathrm{Na}]) \text { mol/liter at } 20^{\circ} \mathrm{C}
$$

and confirmed in Tank 48 precipitation demonstration.

To achieve the cesium DF goal we must also assure that the installed ITP filters have no cracks or leaks and provide a particulate $D E$ at least 40,000 , assuming negligible soluble cesium. A special cross-flow Test Facility was built at TNX (Ref. 3) to test the mechanical integrity and particulate decontamination of new filters as they are received at SRS. However cold chemical ITP filtration tests started before the Test Eacility was complete. This necessitated an alternate approach to demonstrate particulate $D F$ as part of the plant tests. This can be done by measuring the concentrations of particulate potassium tetraphenyl borate (KTPB) used during the cold chemicals test runs since KTPB behaves similarly to cesium forming a fine 0.5 micron precipitate. The ratio of solid KTPB in the feed slurry over particulate KTPB in the filtrate defines particulate DF.

\section{DISCUSSION}

\section{cold Chemical Testing of ITP Filters}

The cold chemical tests were conducted using an "average" hydroxide/nitrate salt composition (Ref 4 ). The initial concentration was approximately $5 \mathrm{M}$ sodium and the slurry contained 1.5 wt: precipitated KTPB. During the testing additional NaTPB and potassium salts were added to increase the insoluble solids to 4 wt $\frac{8}{\circ}$ and then to 10 wt $\%$. Based on actual analyses (Ref 5 ) the final concentration was 8.38 . wt: solids consisting of $67.7 \%$ KTPB and $32.3 \%$ NaTPB. The observed filter flux rate is shown in 
WSRC-RP-93-768

Page 3

May 21, 1993

Figure 1, showing a logarithmic decrease/ with concentration.

Cesium was not included in these test due to slow precipitation equilibrium (Ref 6). Since potassiup behaves similarly to cesium and forms a similar TPB precipitatelit can be used for assessing filter particulate DF. Potassium is normally present in waste solutions at a concentration $100 x$ cesium.

Particulate DF measurements were made on the 8.38 wto slurry and ITP filtrate from that slurry. This allows highest sensitivity for detecting solids in the filtrate.

\section{DF Measurement Requirements}

To estimate particulate decontamination we must know the insoluble KTPB concentration in the slurry and the insoluble (particulate) KTPB concentration in the filtrate. High solids concentration, greater than 1 wt: can be obtained by difference between total KTPB and filtrate KTPB (Ref 7). For the test slurry the potassium concentration was calculated at 5.67 wt: $\mathrm{KTPB}$ or $63.5 \mathrm{~g} / \mathrm{l}$

(Appendix E). The goal for 40,000 particulate DF is $63500 / 40,000=1.6 \mathrm{mg}$ insoluble KTPB per liter of filtrate (0.17 $\mathrm{mg} \mathrm{K} / \mathrm{l})$.

The solubility of KTPB in salt solutions is a function of salt concentration and temperature and can vary between 3 and $12 \mathrm{mg} / \mathrm{l}$ within ITP testing profile, Table 1 (Ref 8). During the ITP tests as the solids concentration was increased the solution concentration decreased from $5 \mathrm{M}$ sodium to about $3 \mathrm{M}$ sodium due to dilution by added ingredients. A measure of total potassium in the filtrate or in solution would provide little guidance to insoluble KTPB.

The high solubility of KTPB makes it also impractical to wash any filtered precipitate. KTPB is significantly more soluble in pure water, about $60 \mathrm{mg} / \mathrm{l}$, than in salt solutions. Saturated wash solution could be used but this would run the risk of introducing potassium to the precipitate, particularly since KTPB can recrystallize at lower temperature.

\section{Sceuting with spiked Filtrate}

Initially three samples were prepared by spiking a nominally clean ITP filtrate (Sample Ox) with 10x KTPB, equivalent to 4000DF, and 100x KTPB, equivalent to $400 \mathrm{DF}$ (Ref 9). The spiked samples were used for evaluating different methods for KTPB analysis, Appendix A.

Scanning Electron Microscopy, showed a well defined crystalline KTPB structure with a narrow crystal size distribution, 0.2 to 1 micron, Figure 2. One drop of $100 x$ sample 
WSRC-RP-93-768

Page 4

May 21, 1993

was filtered and washed with two drops of water. At lower magnifications clusters of crystals were clearly visible, Fig 3A, and they were visible in the actual filtrate suspension using optical microscopy, Fig 3B. Optical viewing under a cover glass allow the only true observation of a filtrate without filtering, washing or drying. However, the 0.5 micron particle size is at the limit of optical resolution and we were not able to find any technique to accentuate the KTPB crystals, e.g. with back lighting or crossed polaroids. KTPB clusters were readily identifiable in the $10 x$ samples, but none were found in the unspiked filtrate indicating visually at least $4000 \mathrm{DF}$.

An attempt to observe KTPB crystals by Transmission Electron Microscopy using liquid sample membrane was not successful probably because the membrane allows evaporation under vacuum resulting in salt crystallization at the surface.

Particle Size Analysis offers a potential tool but meaningful results could not be obtained with the SRTC laser analyzer. However excellent results were obtained using Lab-Tec analyzer at Lockheed Environmental, Fig 4, showing a uniform distribution of clusters up to 60 microns and a significant concentration of particles below 0.7 microns. Similar distribution was found in the $10 \mathrm{x}$ sample. The $0 \mathrm{x}$ filtrate also showed a distribution indicating possible KTPB in the filtrate. Subsequent SEM examination of the $0 x$ filtrate refiltered on $0.2 \mu$ filter medium showed a variety of "junk" such as $\mathrm{Mg}, \mathrm{Al}, \mathrm{Si}, \mathrm{Ca}, \mathrm{Cr}, \mathrm{Fe}, \mathrm{Ni}$, possibly explaining the size distribution in the ox sample. The Lab-Tech instrument was not able to provide a measure of particle concentration. This would have allowed to differentiate quantitatively between the spiked samples.

ICP Mass Spectrometry would have been applicable and useful for analysis of small concentrations in the presence of high levels of sodium, however, the instrument is set up with argon carrier gas, MW 40, and this is too close for effective separation of

potassium, MW 39. Cesium at $M W 45$ can be analyzed readily even at much lower concentrations than potassium.

Neutron Activation was tried at ORNL but the sodium activity overshadowed the potassium. Particulate potassium on a filter paper may be analyzable but this was not tried.

Solid state Track Recording allows the observation of boron in KTPB and NaTPB. Crystalline boron will produce clustered tracks while the boron in solution produces random tracks, allowing the crystals to be counted (Appendix B). Initial results from S\&T Center were promising but not definitive. This method could be developed if necessary to supplant direct $k-40$ counting.

Other techniques were considered and rejected. Prompt Gamma activation at $S \& T$ Center requires a large volume of solution and 
WSRC-RP-93-768

Page 5

May 21, 1993

significant set up time. It was not clear that potassium could be identified in high concentration of sodium. Ion Exchange could be used to take up ionic potassium, but it was unlikely that the insoluble potassium would adsorb on the column.

Natural potassium contains $0.00118 \%$ radioactive $\mathrm{K}-40$ which releases $11 \%$ of its gamma intensity at $1460 \mathrm{KeV}$. This can be counted directly by Low-Level Gamma spectrometry. The ETS Underground Counting Facility can detect $\mathrm{K}-40$ levels down to $1 \mathrm{pCi}$, or about $1 \mathrm{mg}$ natural potassium. Scouting tests using 100 ml of $100 x$ spiked liquid sample showed a measurable $\mathrm{K}-40$ concentration, indicating that 10 liters of $1 \times(40,000$ DF) liquid sample would have a measurable amount of potassium, provided that the volume could be reduced one hundred fold to $100 \mathrm{ml}$ or less without destroying the particulate KTPB. The counting geometry was calibrated with known KTPB slurry and weighed $\mathrm{KCl}$

(Appendix C).

\section{Rarticulate KTPB concentration}

Earlier contacts with Rhone Poulenc to find alternate filtration systems for late washing have identified a compact bench scale cross-flow filtration unit, Appendix D. The units are designed to circulate as little as $100 \mathrm{ml}$ of solution. The filter medium is a thin layer of $\mathrm{ZrO}_{2} / \mathrm{TiO}_{2}$ on porous carbon and porosity is available from 0.45 micron down to 0.08 micron and lower for biological filtration.

For DF measurement four gallons of ITP filtrate sample (SIM-386) was decanted by siphoning off 15 liters for concentration at Rhone-Poulenc. The bottom $780 \mathrm{ml}$ contained a light white precipitate and was kept separately for analysis. The 15 liter sample was then "concentrated" to about $100 \mathrm{ml}$ at Rhone Poulenc by refiltering with 0.14 micron Carbosep(8) membranes. The filter was then rinsed with water for separate potassium analysis. Particulate solids from all three samples (sample bottoms, concentrate, and rinse water) were collected on separate 0.2 micron Millipore fluorocarbon filters and counted together for $\mathrm{K}-40$. The total potassium was less than $2 \mathrm{mg}$, indicating a particulate $\mathrm{DF}>40,000$.

\section{Rest Precipitatien}

Earlier observations have shown that a fine precipitate often appears in retained filtrate samples. This was analyzed earlier to be an aluminum silicate. A small amount of fine precipitate was present in most ITP retained samples including the 4 gal sample used for DF measurement. In this case any precipitated KTPB was less than $2 \mathrm{mg} \mathrm{K}$. However as the sample temperature drops KTPB can be precipitated. About $40 \mathrm{ml}$ was siphoned out from the bottom of 1 gallon SIM 379 retained filtrate. $20 \mathrm{ml}$ was 
WSRC-RP-93-768

Page 6

May 21, 1993

filtered and resulted in $25 \mathrm{mg}$ unwashed solids. Another $20 \mathrm{ml}$ was filtered and washed three times with $20 . \mathrm{ml}$ water each time. The residual dry solids was reduced to $3.5 \mathrm{mg}$ and examined under SEM showing a mass of potassium crystals, Fig 7. Some of the KTPB crystals were exceptionally large, greater than 10 microns, indication a slow crystallization during sample aging at reduced temperature. However aluminum and silicon were also observed confirming earlier analyses.

\section{Alternative Membrane Integrity Testing}

Commercial techniques are available for testing the integrity of filter elements, seals and connections, Ref 10 . These methods require no precipitate and rely on "bubble point" formation or diffusion testing. These tests can be specified for acceptance of new filters.

\section{CONCIUSIONS}

Solids concentration offers a simple and useful technique for analysis of insoluble residues. Direct weighing of the collected solids can provide a guide to the concentration of insoluble solids. Conventional chemical analyses can then be used much more effectively since most of the soluble matrix solution has been removed. It may also be possible to develop quick cold rinsing to wash off the soluble salts and provide a more quantitative measure of retained solids.

\section{REEERENCES}

1. Memorandum, E.B. Snell and C.J. Heng to O.M. Morriss, "Salt Decontamination Demonstration Results", DPSP 83-17-8, 6/20/83.

2. L.M. Lee and L.L. Kilpatrick, "A Precipitation Process for Supernate Decontamination", DP-1636, 11/1982.

3. L.L. Kilpatrick, Job Plan 678-T-91-8-1, 9/09/92.

4. D.D. Walker and G.K. Georgeton "Viscosity and Density of Simulated Salt Solutions" WSRC-RP-89-1088, 10/19/89.

5. E-Mail, D.B. McCabe to L.O. Dworjanyn, 3/3/93.

6. E-Mail, L.L. Kilpatrick to D.F. Brown et al., 4/9/92.

7. E.W. Banwann to W.A. Spencer, "Determination of Tetraphenyl Borate by Potenthouretric Titration with Silver Nitrate", DPST$86-845,12 / 3 / 86$. 
WSRC-RP $-93-768$

Page 7

May 21, 1993

8. L.O. Dworjanyn, "Review of Tetraphenyl Borate Solubilities", WSRC-RP-93-1001 to be issued.

9. M.J. Barnes, Research Notebook - WSRC-NP-90-161, pages 113 to $115,11 / 11 / 92$.

10. Millipore Direct Catalog, 1991-1992, pages 10 to 11. 
KTPB Solubility in Salt Solutions

\begin{tabular}{|c|c|c|c|c|c|c|c|c|}
\hline Temp & {$[\mathrm{Na}]$} & 0 & 1 & 2 & 3 & 4 & 5 & 6 \\
\hline${ }^{\circ} \mathrm{C}$ & ${ }^{\circ} \mathrm{K}$ & $\mathrm{mol} / \mathrm{e}$ & & & & & & \\
\hline 0 & 273.15 & $1.29 \mathrm{E}-04$ & 7.00E-05 & 3.81E-05 & 2.07E-05 & $1.12 E-05$ & $6.10 E-06$ & $3.32 \mathrm{E}-06$ \\
\hline 5 & 278.15 & $1.30 E-04$ & $7.08 E-05$ & 3.85E-05 & $2.09 E-05$ & $1.14 E-05$ & $6.17 E-06$ & $3.35 \mathrm{E}-06$ \\
\hline 10 & 283.15 & 1.35E-04 & 7.36E-05 & $4.00 E-05$ & 2.17E-05 & $1.18 E-05$ & $6.42 E-06$ & $3.49 E-06$ \\
\hline 15 & 288.15 & $1.44 \mathrm{E}-04$ & $7.84 \mathrm{E}-05$ & 4.26E-05 & 2.32E-05 & $1.26 \mathrm{E}-05$ & $6.83 E-06$ & 3.71E-06 \\
\hline 20 & 293.15 & $1.57 E-04$ & 8.54E-05 & 4.64E-05 & $2.52 E-05$ & 1.37E-05 & $7.44 \mathrm{E}-06$ & $4.04 E-06$ \\
\hline 25 & 298.15 & $1.75 \mathrm{E}-04$ & $9.49 E-05$ & 5.16E-05 & $2.80 \mathrm{E}-05$ & $1.52 E-05$ & 8.27E-06 & 4.49E-06 \\
\hline 30 & 303.15 & $1.97 E-04$ & $1.07 E-04$ & 5.83E-05 & 3.17E-05 & $1.72 E-05$ & $9.35 E-06$ & $5.08 E-06$ \\
\hline 35 & 308.15 & 2.27E-04 & $1.23 E-04$ & 6.70E-05 & $3.64 E-05$ & $1.98 E-05$ & 1.07E-05 & $5.84 \mathrm{E}-06$ \\
\hline 40 & 313.15 & $2.64 \mathrm{E}-04$ & $1.44 \mathrm{E}-04$ & $7.80 E-05$ & 4.24E-05 & 2.30E-05 & $1.25 E-05$ & $6.80 E-06$ \\
\hline 45 & 318.15 & $3.12 E-04$ & $1.69 \mathrm{E}-04$ & $9.20 \mathrm{E}-05$ & $5.00 \mathrm{E}-05$ & $2.72 E-05$ & $1.48 E-05$ & $8.02 E-06$ \\
\hline 50 & 323.15 & $3.72 E-04$ & 2.02E-04 & $1.10 \mathrm{E}-04$ & 5.97E-05 & $3.24 E-05$ & $1.76 E-05$ & 9.57E-06 \\
\hline Temp & {$[\mathrm{Na}]$} & 0 & 1 & 2 & 3 & 4 & 5 & 6 \\
\hline${ }^{\circ} \mathrm{C}$ & ${ }^{\circ} \mathrm{K}$ & $\mathrm{mg}$ KTPB & & & & & & \\
\hline 0 & 273.15 & 46.2 & 25.1 & 13.6 & 7.41 & 4.03 & 2.19 & 1.19 \\
\hline 5 & 278.15 & 46.7 & 25.4 & 13.8 & 7.49 & 4.07 & 2.21 & 1.20 \\
\hline 10 & 283.15 & 48.5 & 26.4 & 14.3 & 7.79 & 4.23 & 2.30 & 1.25 \\
\hline 15 & 288.15 & 51.7 & 28.1 & 15.3 & 8.30 & 4.51 & 2.45 & 1.33 \\
\hline 20 & 293.15 & 56.3 & 30.6 & 16.6 & 9.03 & 4.91 & 2.67 & 1.45 \\
\hline 25 & 298.15 & 62.6 & 34.0 & 18.5 & 0006 & 6.45 & 206 & 1.61 \\
\hline 30 & 303.15 & 70.7 & 38.4 & 20.9 & 18 & 6.6 & 3. & 1.82 \\
\hline 35 & 308.15 & 81.3 & 44.2 & 24.0 & 180. & 1.38 & 3.85 & 2.09 \\
\hline 40 & 313.15 & 94.7 & 51.4 & 28.0 & 15.19 & 8.25 & 4.48 & 2.44 \\
\hline 45 & 318.15 & 111.7 & 60.7 & 33.0 & 17.92 & 9.74 & 5.29 & 2.87 \\
\hline 50 & 323.15 & 133.3 & 72.4 & 39.3 & 21.38 & 11.62 & 6.31 & 3.43 \\
\hline
\end{tabular}

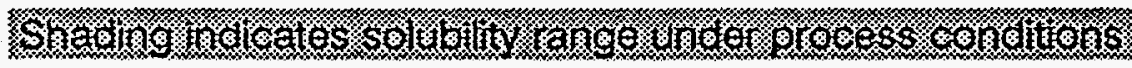


FIGURE 1

ITP Filtrate Flux Unit \#3 STRIP.WQ1 LOG_FIT

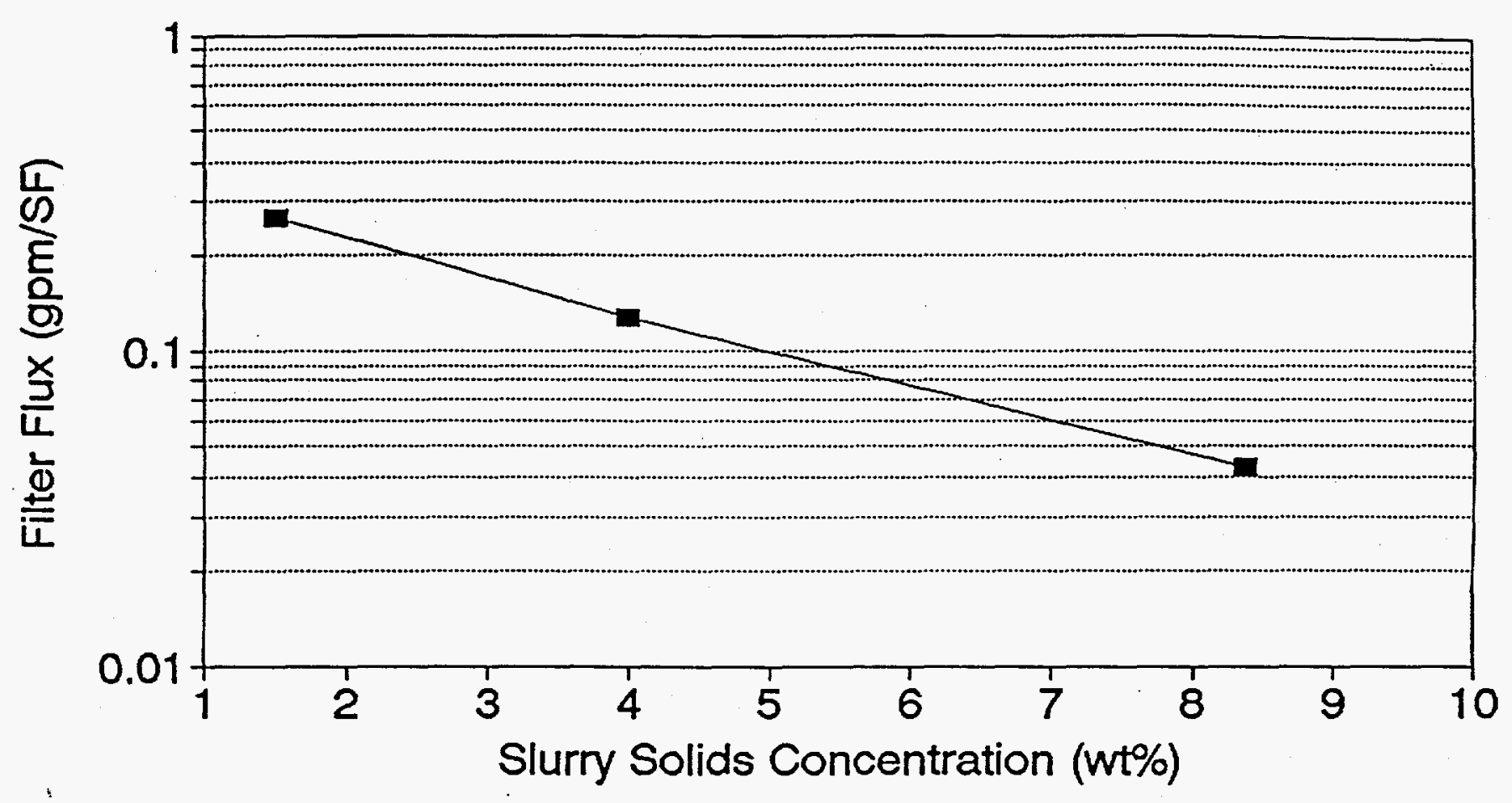

$\rightarrow$ ITP Data 
FIGURE 2

$100 x$ spiked KTPB
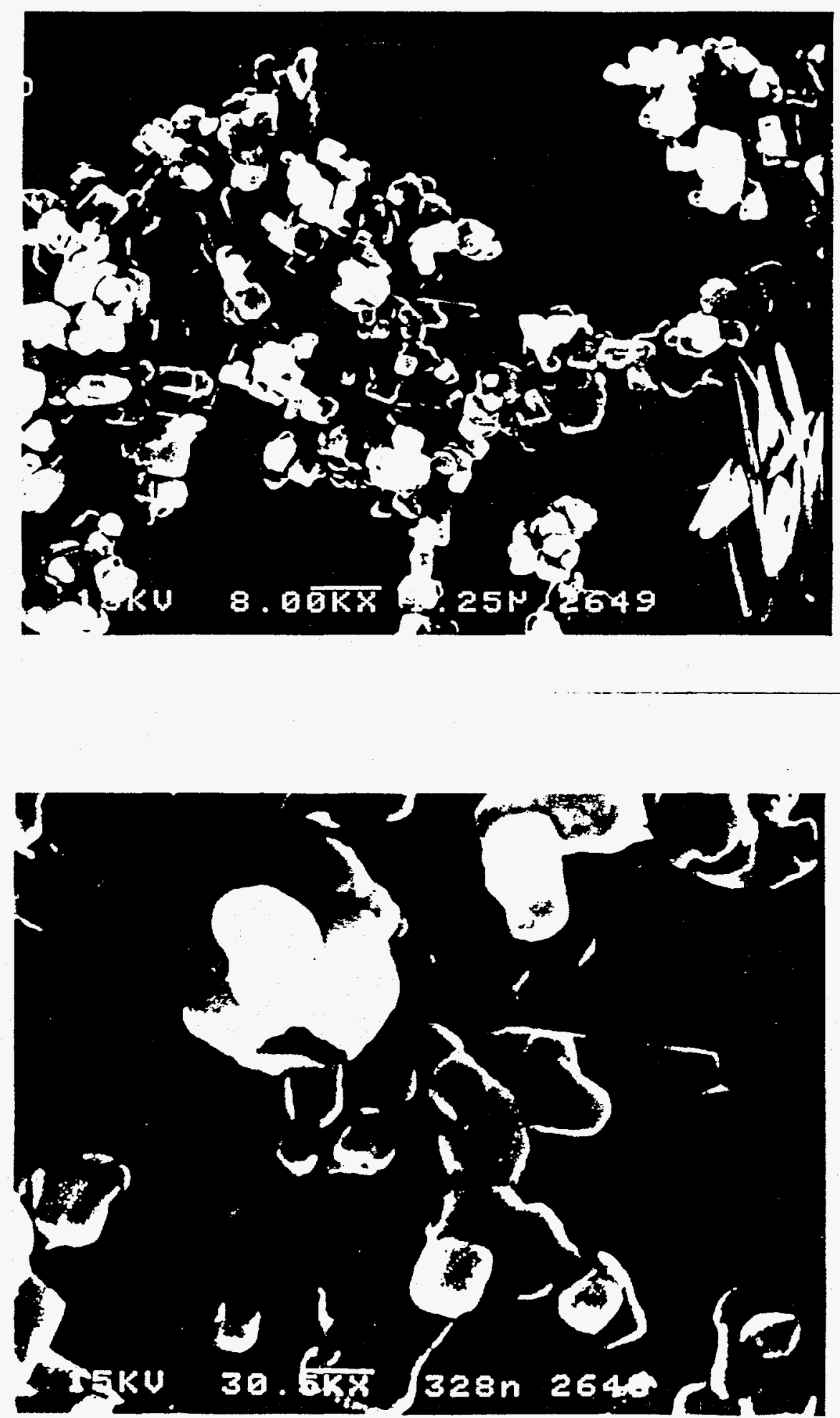


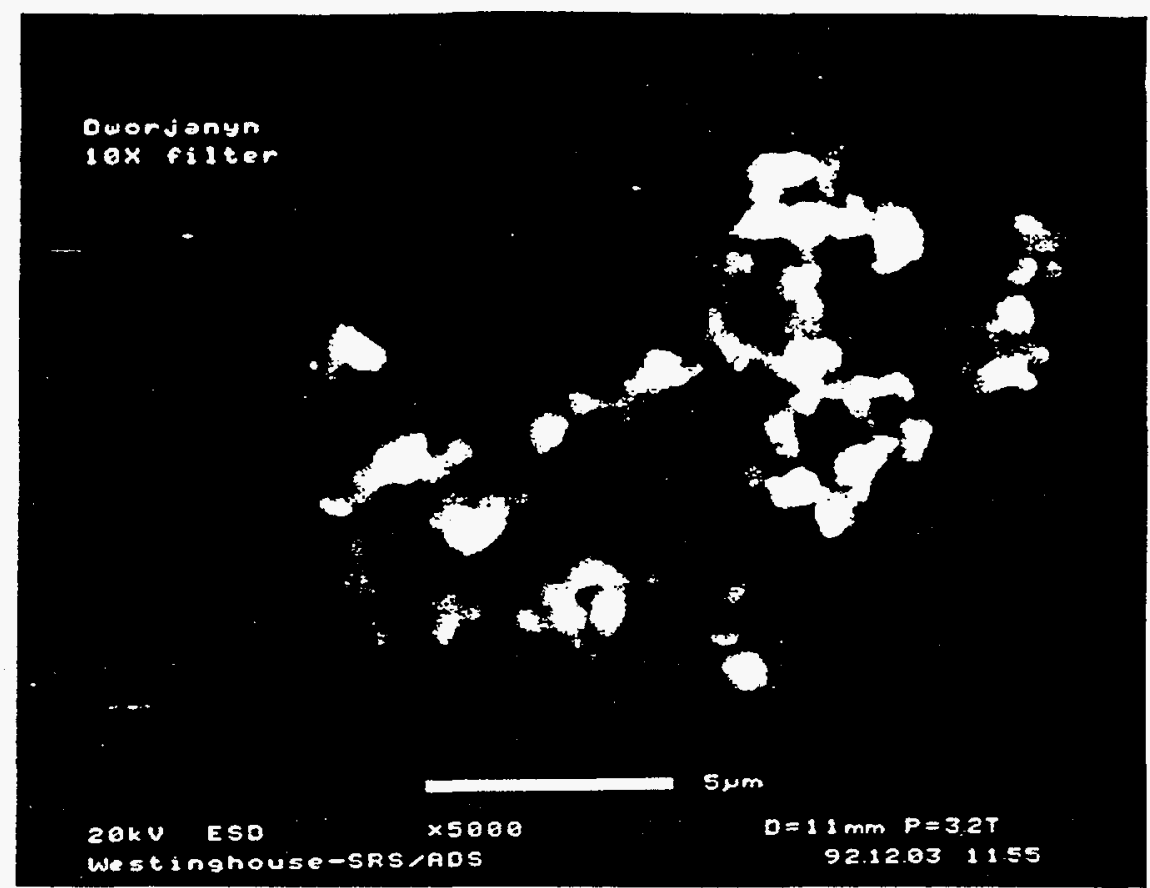

3A. SEM

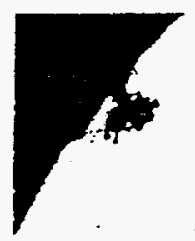

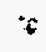

$\therefore$
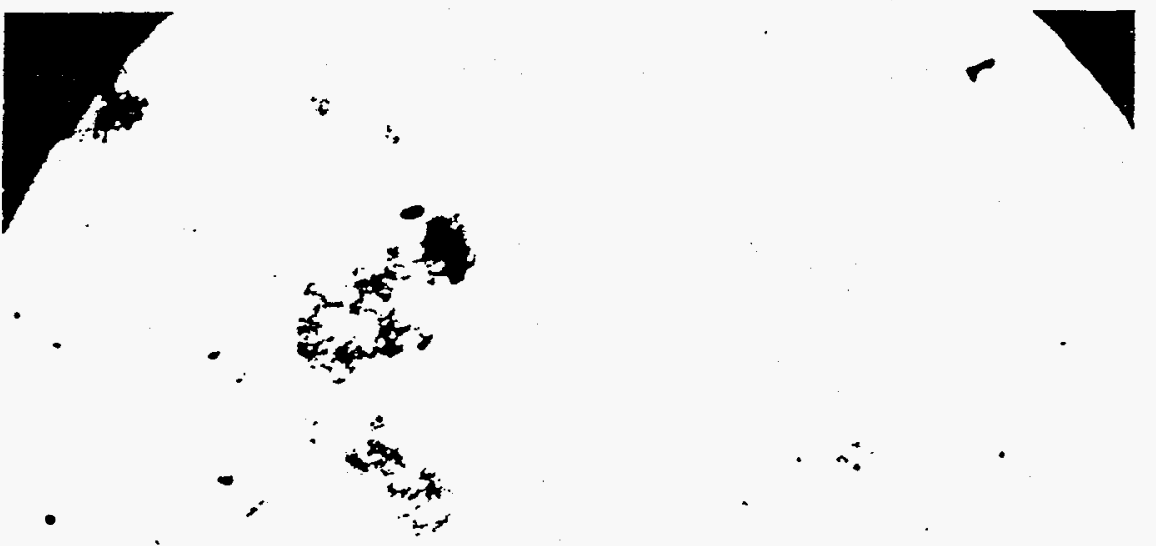

I

$+$

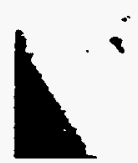

3B. OPTICAL 
Lockheed Environmental Services and Technology Company Technology Demonstration and Remediation Division

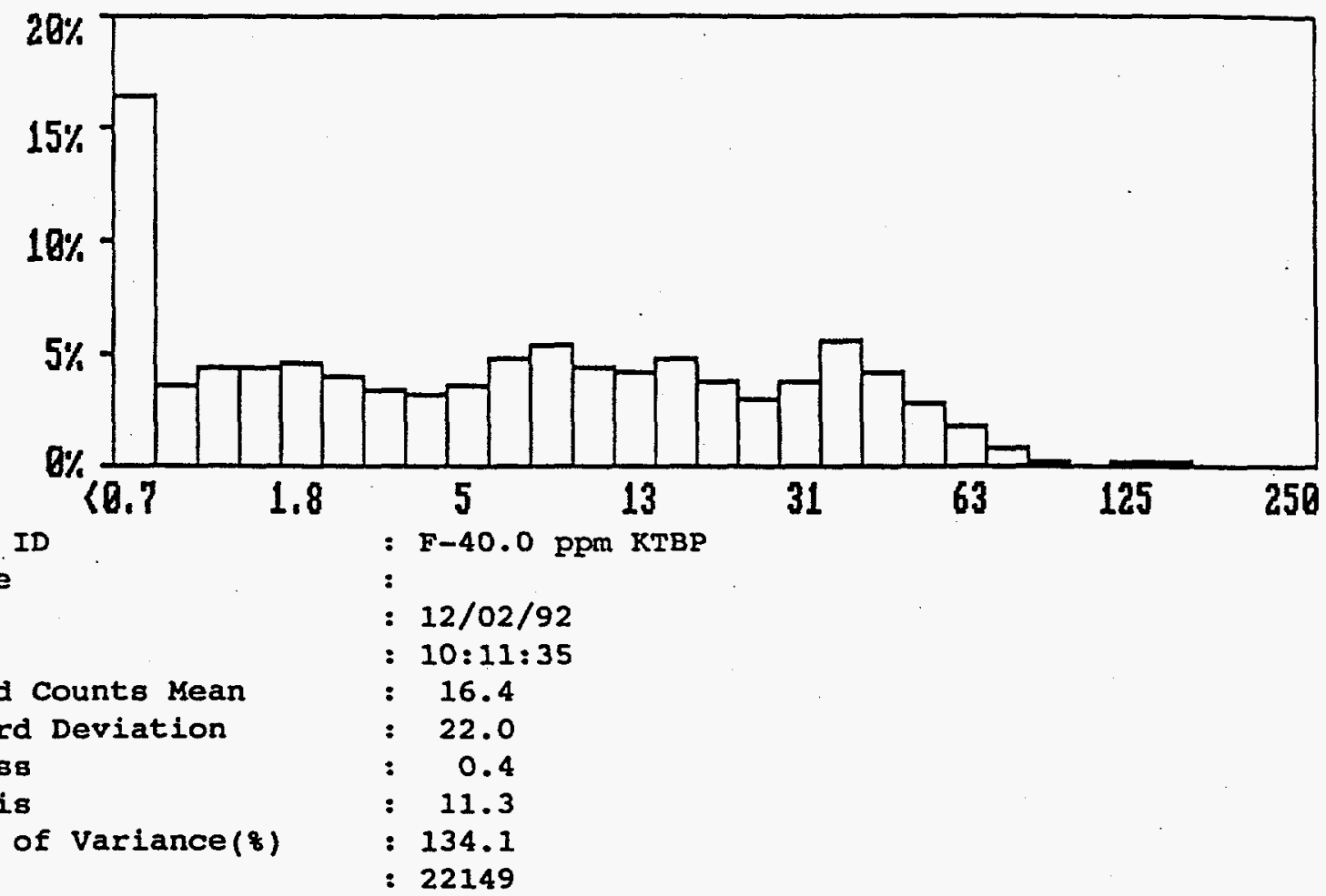

Sample ID

: F-40.0 ppm KTBP

CF Code

Date

Time

Scanned Counts Mean

standard Deviation

Skewness

Kurtosis

Coeff. of Variance $(\&)$

counts

: 22149

$\begin{array}{ll}\text { Cycles } & : 13 \\ \text { Scaling } & : 1.00\end{array}$

M. Cycle Time: $1.0 \mathrm{sec}$.

Averaged last 10 cycle(s)

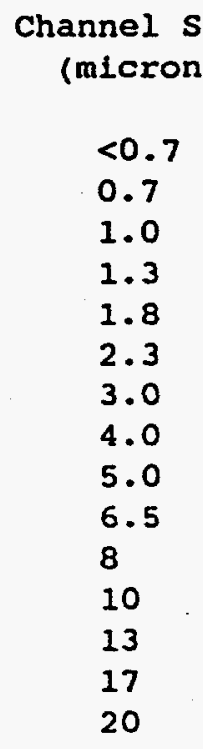

8/Channel

Channel size

8/Channel (microns)

16.4984

25

31

37

44

53

63

75

88

105

125

149

177

210

250

3.1668

3.9628

5.7516

4.3373

2.9149

1.9974

0.9627

0.2791

0.1011

3.6861

0.2350

5.4044

0.3054

4.4694

0.0000

4.2380

0.0000

4.8632

3.8072

0.0000

100x Particle Size Distribution 
Lockheed Environmental Services and Technology Company Technology Demonstration and Remediation Division

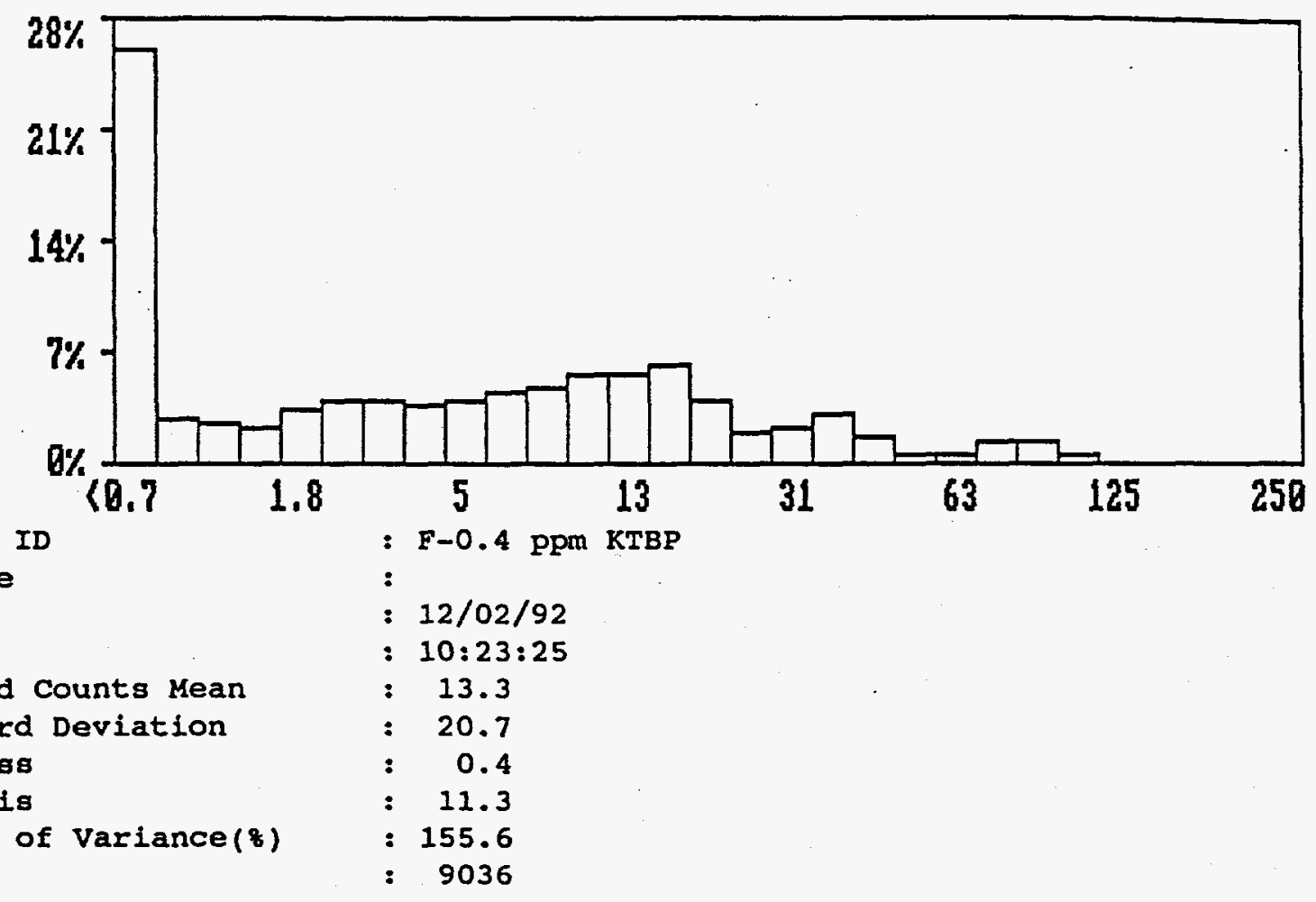

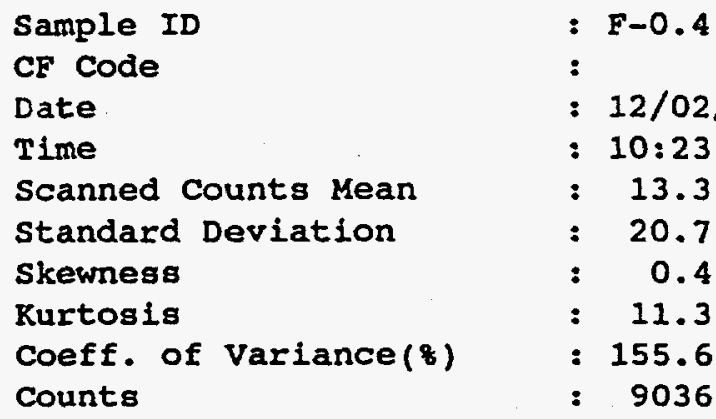

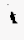

$\begin{array}{ll}\text { Cycleg } & : 12 \\ \text { scaling } & : 1.00\end{array}$

M.Cycle Time: $1.0 \mathrm{sec}$.

Averaged last 10 cycle(s)

Channel size

8/Channel

Channel size (microns)

26.3041

2.8503

2.6985

2.4262

3.3884

3.9856

4.1114

3.8503

4.0846

4.6155

5.0328

5.8542

5.8506

6.1902

3.9871
25

31

37

44

53

63

75

88

105

125

149

177

210

250
$8 /$ Channel

2.1884

2.4844

3.1986

1.8310

0.7377

0.6619

1.5176

1.4751

0.5643

0.1111

0.0000

0.0000

0.0000

0.0000

0x Filtrate Particle Distribution 
SERIES II

WEL $D E-D E C-S 2 \quad 14: 15$

Cursar: 0 . Dookev = 0

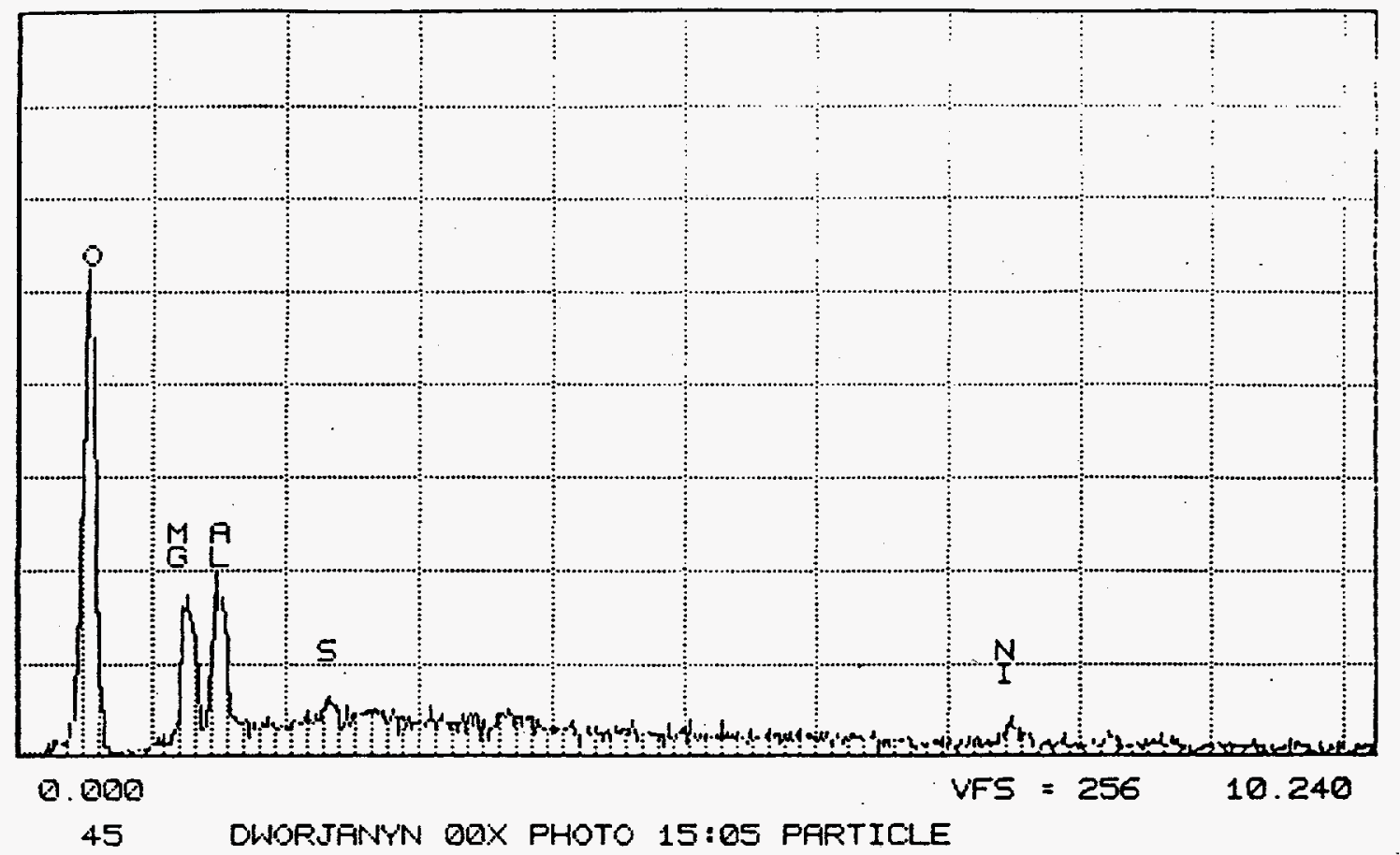

SERIES II

WED $\triangle 2-D E C-92 \quad 14: 22$

Cursor: 0.000keV =

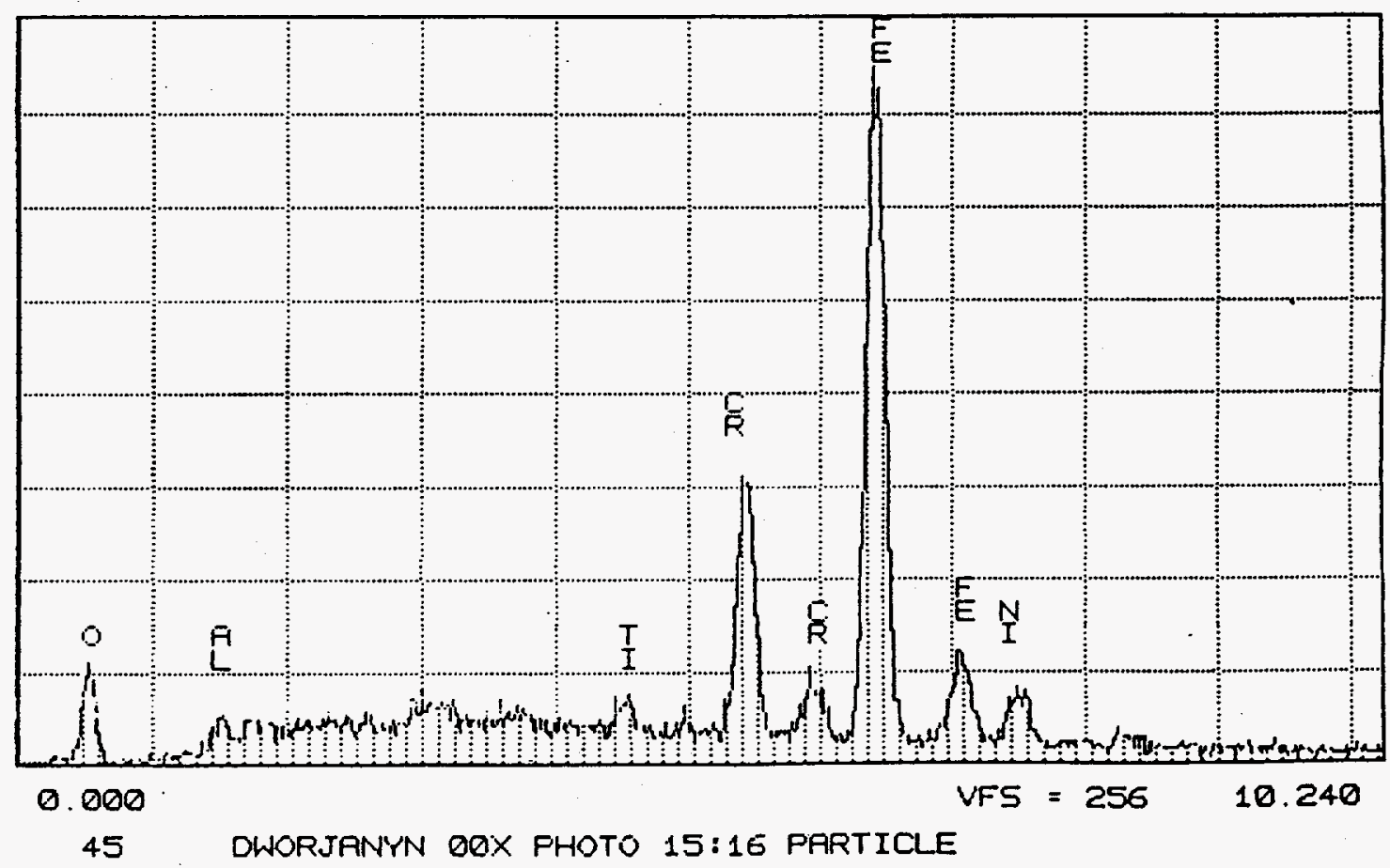

Junk in Filtrate 


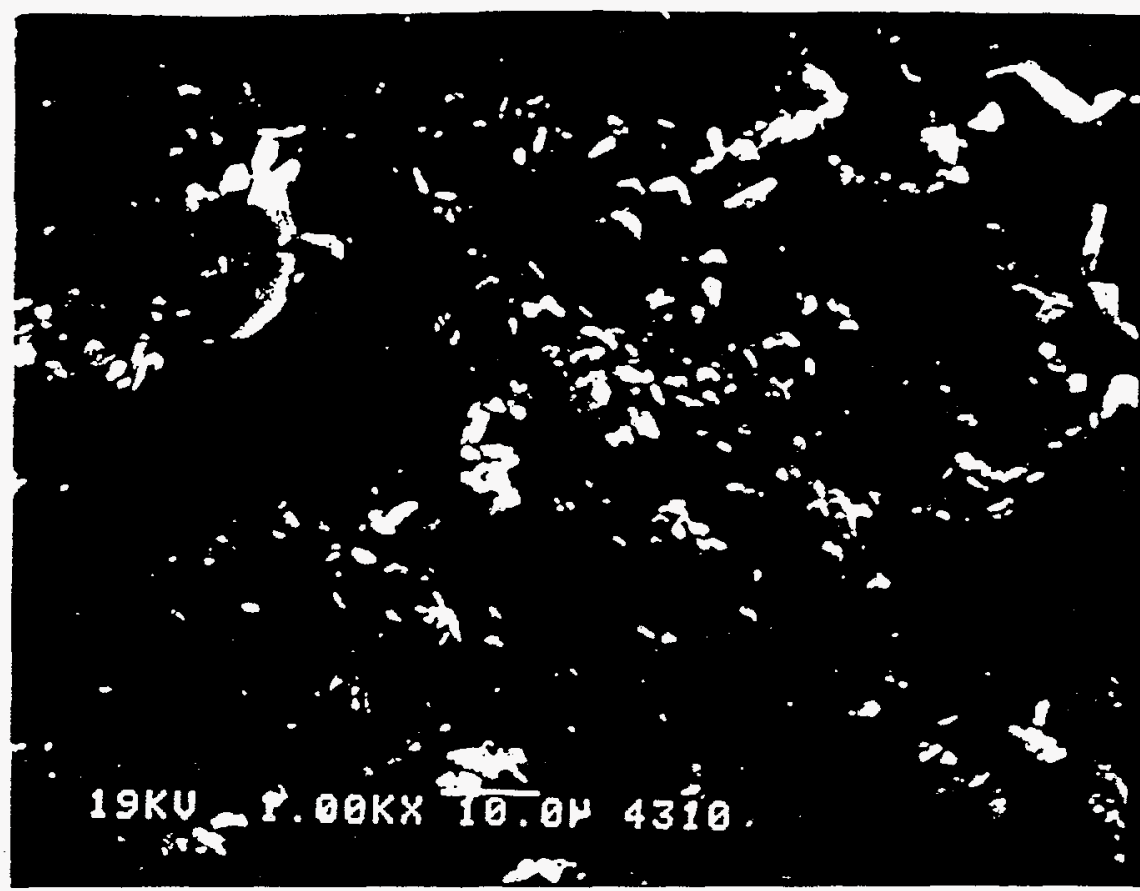

Washed Post Precipitate

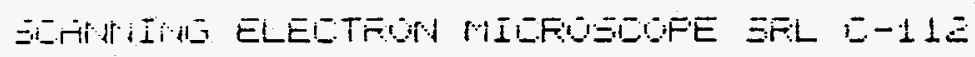
FF:I $\quad 30-A F F-O S$

$16: 05$

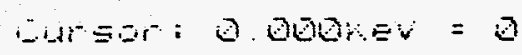

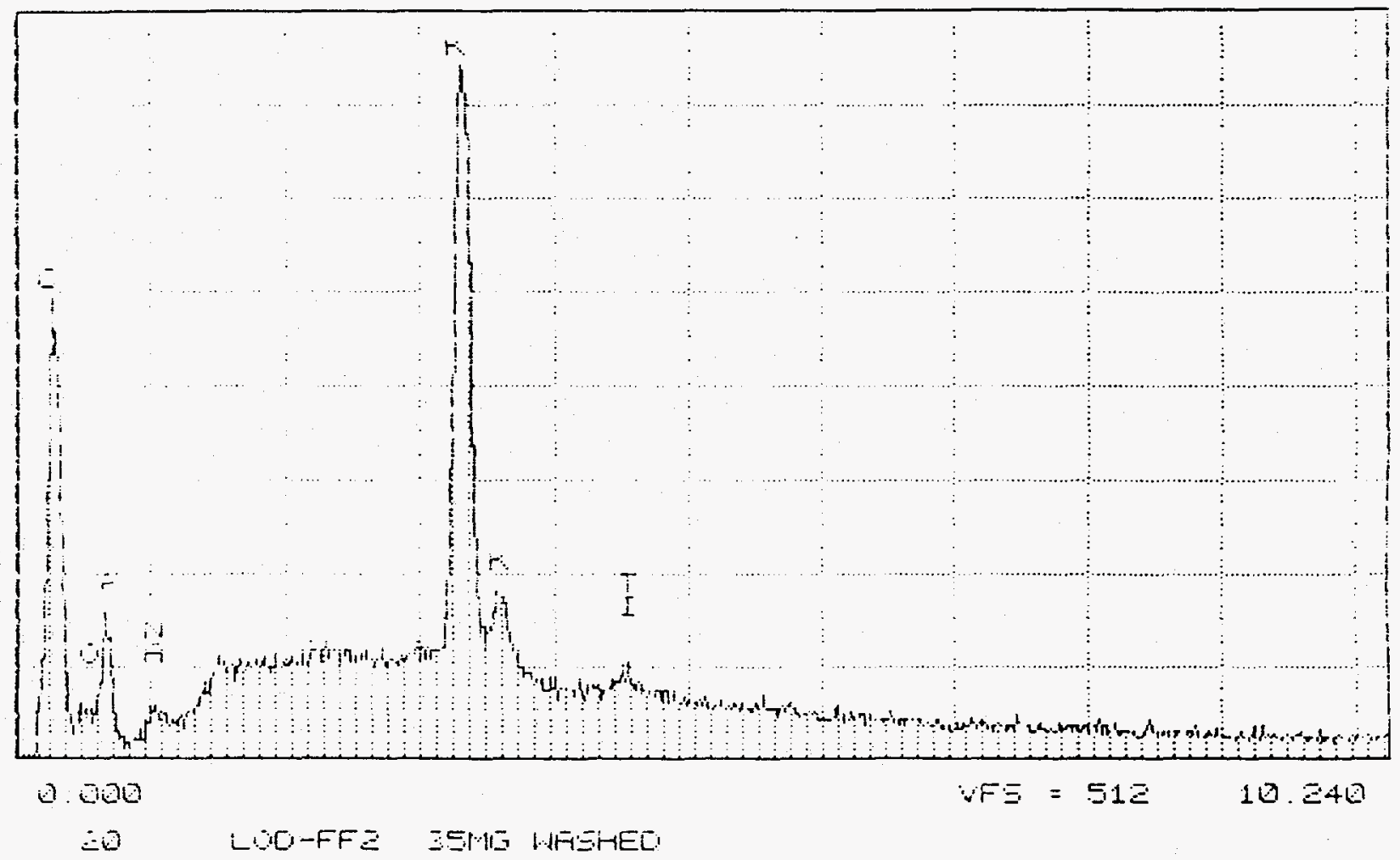

Microprobe Analysis 


\section{Techniques for Potassium Measurement}

\begin{tabular}{|c|c|c|}
\hline Analytical Method & Capability & Comments \\
\hline $\begin{array}{r}\text { Direct } \mathbf{K}^{\mathbf{4 0}} \text { Activity } \\
\text { Bill Winn, ET } \\
\end{array}$ & $\begin{array}{l}\text { Direct Potassium measurement } \\
725-2057 \\
\end{array}$ & $\begin{array}{l}\text { Detect } 100 \mathrm{X} \text { sample } \\
\text { Need } 100 \mathrm{X} \text { concentration }\end{array}$ \\
\hline $\begin{array}{l}\text { Neutron Activation of filter paper w/ppt } \\
\text { Paul Cloessner/Marti Finney, ADS } \\
\text { Larry Robinson, ORNL }\end{array}$ & $\begin{array}{l}\mathrm{K}, \mathrm{Cs} \\
725-2198 / 9656 \\
(615) 574-4912 \\
\end{array}$ & $\begin{array}{l}\text { Direct K measurement in } \mathrm{Na} \text { matrix not } \\
\text { possible. Unwashed } \mathrm{K} \text { particulates on filter } \\
\text { paper: Na still too high. }\end{array}$ \\
\hline $\begin{array}{l}\text { Solid State Track Recording of paper } \\
\text { Frank Ruddy, S\&TC }\end{array}$ & \begin{tabular}{|l|} 
Identify Boron Crystals \\
$(412) 256-1064$ \\
\end{tabular} & $\begin{array}{l}\text { Direct B crystal count not effective. } \\
\text { Need ppte on filter paper. }\end{array}$ \\
\hline $\begin{array}{l}\text { Scanning Electron Microscopy } \\
\text { Dan Steedly, ADS }\end{array}$ & $\begin{array}{l}\text { Observation of particulates onn filter paper } \\
725-2324\end{array}$ & $\begin{array}{l}\mathrm{K} \text { particles observed in } 10 \mathrm{X} \text { and } 100 \mathrm{X} \\
\text { spiked samples. None in ITP filtrate. }\end{array}$ \\
\hline $\begin{array}{r}\text { Optical Microscopy } \\
\text { Cliff Carlson, ET }\end{array}$ & $\begin{array}{l}\text { Liquid sample observation and count. } \\
725-5416\end{array}$ & $\begin{array}{l}\mathrm{K} \text { agglomerates observed in } 10 \mathrm{X} \text { and } \\
100 \mathrm{X} \text { spiked samples. }\end{array}$ \\
\hline $\begin{array}{l}\text { ICP Mass Spectrometry } \\
\text { Justin Halverson, ET } \\
\end{array}$ & $\begin{array}{l}\text { Argon carrier gas interferes with } \\
\text { potassium measurement. 5-9625 }\end{array}$ & $\begin{array}{l}\text { No Cs in cold feed } \\
\text { Needs development }\end{array}$ \\
\hline $\begin{array}{l}\text { Transmission Electron Microscopy } \\
\text { Mike Tosten, MT }\end{array}$ & $\begin{array}{l}\text { Liquid sample observation } \\
725-6230 \\
\end{array}$ & $\begin{array}{l}\text { Potassium masked by sodium salt } \\
\text { crystallization. }\end{array}$ \\
\hline $\begin{array}{l}\text { Fourier Mass Spectrometery } \\
\text { Bob Weller, ET } \\
\text { Michelle Buchannan, ORNL }\end{array}$ & $\begin{array}{l}\text { Accurate } \mathrm{Cs} \text { and } \mathrm{K} \text { determination } \\
725-9557 \\
(615) 574-4868 \\
\end{array}$ & $\begin{array}{l}\text { SRTC instrument not available for at least } \\
\text { six months }\end{array}$ \\
\hline $\begin{array}{c}\text { Analytical after IX on column } \\
\text { Chuck Coleman, ADS }\end{array}$ & Selective adsorption and analysis & $\begin{array}{l}\text { Not effective on particulate, } \\
\text { needs development. }\end{array}$ \\
\hline $\begin{array}{l}\text { Prompt Gamma Neutron Activation } \\
\text { Frank Ruddy, S\&TC } \\
\end{array}$ & $\begin{array}{l}\text { Used for soil analysis. Need large volume } \\
\text { eg. } 2 \mathrm{~m}^{3} \text { soil }\end{array}$ & High setup and development \\
\hline $\begin{array}{l}\text { Particle size analysis } \\
\text { John Domenech, Lockheed Env. }\end{array}$ & $\begin{array}{l}\text { Size analysis without dilution } \\
\text { (702) } 361-0740\end{array}$ & $\begin{array}{l}\text { Works directly on } 10 \mathrm{X} \text { to } 100 \mathrm{X} \text { filtrate. } \\
\text { Cannot distinguish from filtrate "trash". }\end{array}$ \\
\hline $\begin{array}{l}\text { Laser Particle Size Analysis } \\
\text { Jane Bibler }\end{array}$ & Particle size distribution $>1 \mu \mathrm{m}$ & Unable to interpret optical data. \\
\hline $\begin{array}{l}\text { TNX Leak Test } \\
\text { Lester Kilpatrick }\end{array}$ & Particulate $\mathrm{K}$ in filtrate & $\begin{array}{l}\text { Requires filter relocation to TNX, or } \\
\text { equipment setup in ITP Area. }\end{array}$ \\
\hline
\end{tabular}

Dworjanyn E:LAPPITPITT_DF.DOC 


\title{
RESULTS OF KTBP ANALYSIS USING SOLID STATE TRACK RECORDERS
}

\author{
F. H. Ruddy \\ (W) STC (412) 256-1064
}

In December of 1992, initial measurements were conducted to develop a new method for analysis of potassium precipitated as KTBP. The method is based on assay of boron in KTBP using the following reastion:

$$
{ }^{10} \mathrm{~B}+\mathrm{n}+{ }^{7} \mathrm{Li}+{ }^{4} \mathrm{He}
$$

The energetic ${ }^{4}$ He nucleus (alpha particle) produced can be detected by means of a Solid State Track Recorder (SSTR). CR-39 polymer SSTRs are sensitive to alpha particles such as those produced in the above reaction, and can therefore be used to detect boron $\left({ }^{10} \mathrm{~B}\right)$ or to detect KTBP via its boron content.

Three solutions were supplied, labeled as follows:

$$
\begin{aligned}
& \text { (1) 00X filtrate } 0.4 \mathrm{ppm} \mathrm{KTBP} 1.17 \mathrm{~g} / \mathrm{cc} \mathrm{NaNO}_{3}, \mathrm{NaOH} \\
& \text { (2) 10X filtrate } 4 \mathrm{ppm} \mathrm{KTBP} 1.17 \mathrm{~g} / \mathrm{cc} \mathrm{NaNO}, \mathrm{NaOH} \\
& \text { (3) 100X Filtrate } 40 \mathrm{ppm} \mathrm{KTBP} 1.17 \mathrm{~g} / \mathrm{cc} \mathrm{NaNO}, \mathrm{NaOH}
\end{aligned}
$$

CR-39 polymer SSTR strips with approximate dimensions $1 \mathrm{~cm} \times 1 \mathrm{~cm} \times$ $0.1 \mathrm{~cm}$ were imersed in each of the three solutions and a "blank" solution made at STC, which contained a solution made by mixing two parts water with one part $6 \mathrm{~N} \mathrm{NaOH}$ solution. After the SSTRs were placed in the vials, the solutions were agitated, and then allowed to settle in a position that would allow particles to come to rest on the SSTR top surface. All four solution bottles were positioned inside of a polyethylene-walled thermalization cavity and bombarded with neutrons originating from a $14 \mathrm{MeV} \mathrm{D-T} \mathrm{neutron} \mathrm{generator.} \mathrm{The} \mathrm{samples} \mathrm{were}$ irradiated for a total of 2500 seconds at the full neutron generator 
power of $1 \times 10^{8}$ neutrons per second. The resulting thermal neutron fluence within the thermalizing cavity was measured using ${ }^{235} \mathrm{U}$ SSTRs.

After the neutron irradiation, the CR-39 polymer SSTRs were etched with $6 \mathrm{~N} \mathrm{NaOH}$ for 2 hours at $70^{\circ} \mathrm{C}$ to develop the alpha tracks produced by neutron reactions in boron. The SSTRs were then manually scanned with an optical microscope to determine the number of alpha particles present. Because boron is expected to be present in solution, only correlated clusters of two or more tracks were counted. The clusters correspond to concentrated boron in precipitated form.

For solution (3), a total of 41 clusters were observed in an SSTR area of $0.55 \mathrm{~cm}^{2}$, and for solution (1), 5 clusters were found in an area of $0.52 \mathrm{~cm}^{2}$. Although the track densities, $74.5 \pm 11.6$ and $9.6 \pm 4.3$, respectively, are not inconsistent with the expected KPTB amounts present, the method lacks sufficient sensitivity as presently applied.

The sensitivity of the method would improve by many orders of magnitude if the solution were filtered, and the analysis were carried out on the filter paper. In the preliminary measurements, only those precipitate particles which were settled out on or were within about 20 microns of the SSTR surface could be detected, because of the limited range of the alpha particle in the solution.

The conclusions of these preliminary measurements are:

(1) The SSTR boron analysis method is capable of detecting KTBP particles, but lacks the required sensitivity when solutions are viewed directly.

(2) The method would undoubtedly yield satisfactory results if the particles were filtered before analysis. 
WESTINGHOUSE SAVANNAH RIVER COMPANY SAVANNAH RIVER TECHNOLOGY CENTER
SRTC-ETS-93156

CC: W.L. Tamosaitis, 773-A

A.L. Boni, 773-A

J.E. Halverson, 735-A

ETS Files, 735-A

May 10, 1993

TO: L.O. DWORJANYN, 779-2A

FROM: W.G. WINN, 735-A ZNA

Low-Level Gamma spectrometry of $\mathrm{R}-40$

for Appraisal of DWPF/ITP Filters

A number of samples have been counted for IWT to appraise the performance of filters to be used for removing cesium/potassium tetraphenyl-borate precipitates after In Tank Precipitation for DWPF. Particulate potassium salt in the filtrate serves as a measure of the filter efficiency and the expected decontamination factor. Naturally occurring $K-40$ can be counted to measure the amount of particulate potassium collected.

The low-level gamma spectrometric capabilities of the ETS Underground counting Facility allow quantifying K-40 at levels as low as $1 \mathrm{pci}$. Coupling this sensitivity with techniques for evaporative concentration of a liquid sample on a small area $\left(\sim 10 \mathrm{~cm}^{2}\right)$ has resulted in demonstrating DF's in excess of 40,000 for the filters studied. A chronological summary of the measurements on IWT test samples is given in Table 1, where brief comments identify the samples according to IWT sample labels.

The sample analyses in the Underground counting Facility utilized a passive/active-shielded HPGe detector with $90 \%$ standard efficiency relative to a 3 " $\times 3 "$ NaI(TI) detector. The counting chamber is $50 \mathrm{ft}$ below ground, and is shielded by lowbackground materials (4" thick pre-WWII steel walls surrounded by 4-7 ft of specular hematite). The facility is constructed as a class 10,000 Clean Room, and the detector sample cavities are purged of radon backgrounds with nitrogen that evaporates from the detector dewars. The detector used in this work is constructed with low-background materials.

The above facility/detector design features reduce the backgrounds from cosmic-rays, natural radioactivity, and local 
sources by orders of magnitude. Because the facility is well isolated from backgrounds from surface effects, the resulting: low background is quite constant and thus suitable for long sample counting. In the present work, sample counting of 1-3 days was used. Because of a small $\mathrm{K}-40$ contribution in the background, special background counts were conducted to affirm its value.

The counting geometries for these samples approximated those for which calibrations had been measured; in particular, a $3.2 \mathrm{~cm}$ diameter vial, calibrated as a function of sample filling, was assumed suitable for both liquid and filter samples. As a check, a filter sample standard of $21.7 \mathrm{mg} \mathrm{K}$ was counted, yielding a value of $16.3 \pm 1.0 \mathrm{pCi}$ for $\mathrm{K}-40$, which is in reasonable agreement with $18.2 \mathrm{pCi}$ calculated from the natural $\mathrm{K}-40$ component of $\mathrm{K}$. Based on this calibration check, a multiplicative correction factor of $1.12 \pm 0.07$ might be applied to the $K-40$ values of Table 1; however, such a correction is not very significant relative to the present study, and the correction factor is within $2 \sigma$ of 1.00 which corresponds to no correction. Accordingly, no renormalization of the data has been applied.

Table 1. K-40 Results for IWT Filter studies

\begin{tabular}{|c|c|c|c|}
\hline Sample & Date & $K-40$ & Comments \\
\hline 1 & $12 / 11 / 92$ & $2.0 \pm 0.6$ & Caustic 100X filtrate 40ppm KTBP \\
\hline 2 & $2 / 2 / 93$ & $<1.6$ & 0.14 filtrate ITP-04I \\
\hline 3 & $2 / 3 / 93$ & $<1.5$ & 0.14 conc 11 ITP-041 \\
\hline $\begin{array}{l}4 \\
4 \mathrm{~A}\end{array}$ & $\begin{array}{l}4 / 2 / 93 \\
4 / 5 / 93\end{array}$ & $\begin{array}{l}<1.6 \\
<1.0\end{array}$ & $\begin{array}{l}\text { K-40 residue / overnite count } \\
\text { / weekend count }\end{array}$ \\
\hline 5 & $4 / 28 / 93$ & $<1.6$ & $0.7 \mathrm{~g}$ disk sample \\
\hline 6 & $4 / 30 / 93$ & $14.3 \pm 1.3$ & -20 mg $\mathrm{K}$ disk sample from slurry \\
\hline 7 & $5 / 3 / 93$ & $<1.0$ & $23 \mathrm{mg}$ conc from $4 \mathrm{gal} \mathrm{SIM}-386 / \mathrm{disk}$ \\
\hline 8 & $5 / 5 / 93$ & $16.3 \pm 1.1$ & $21.7 \mathrm{mg} \mathrm{K}$ of $\mathrm{KCl}$ on disk \\
\hline
\end{tabular}




\section{GENERAL DESCRIPTION}

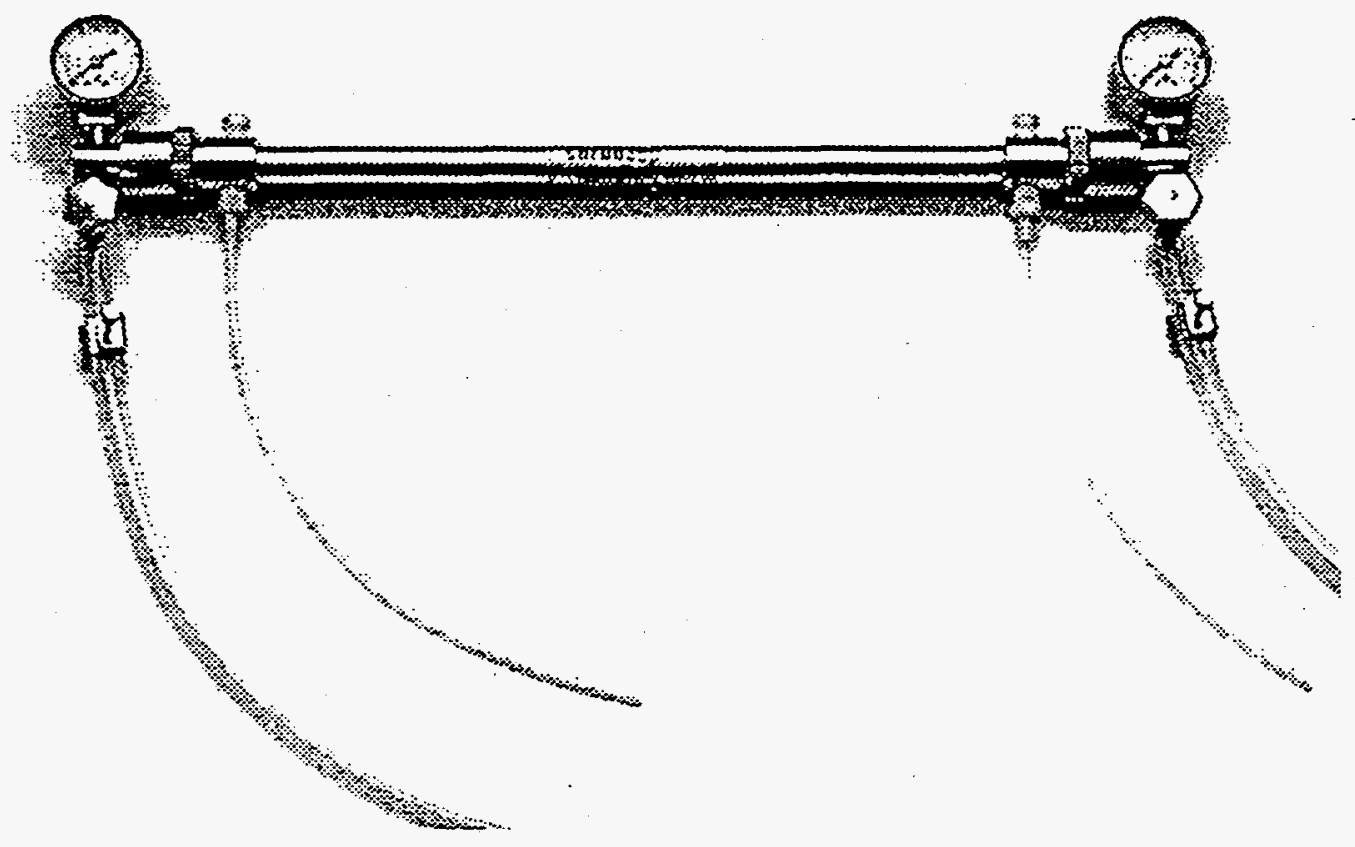

MICRO-CARBOSEP ${ }^{\oplus} 20,40$ and 60 are tubular ultrafiltration and microfiltration modules, specially designed for processing small quantities. They are multi-purpose, easily adaptable and compact. and are an ideal tool for research laboratories. They are particularly suitable for feasibility studies.

The system can be sterilized in an autoclave and can process a wide variety of fluids. With a liquid channel 0.5 or $6 \mathrm{~mm}$ thick. it can operate at low pressure (<1.5 bar) or high pressure ( $1.5 \mathrm{bar}$ ), at a low $(30 \mathrm{Vh})$ or high $(500 \mathrm{Vh})$ recirculation rate, depending on the product to be processed. It can stand on any laboratory bench and can be fed with a peristaltic pump found in all laboratories (see Appendix II). 
E:VAPPITPIDF.WO1

$K$ Mol Wr

KTPB Mol Wt

B35: $\quad 39.09$

B36: 358.32

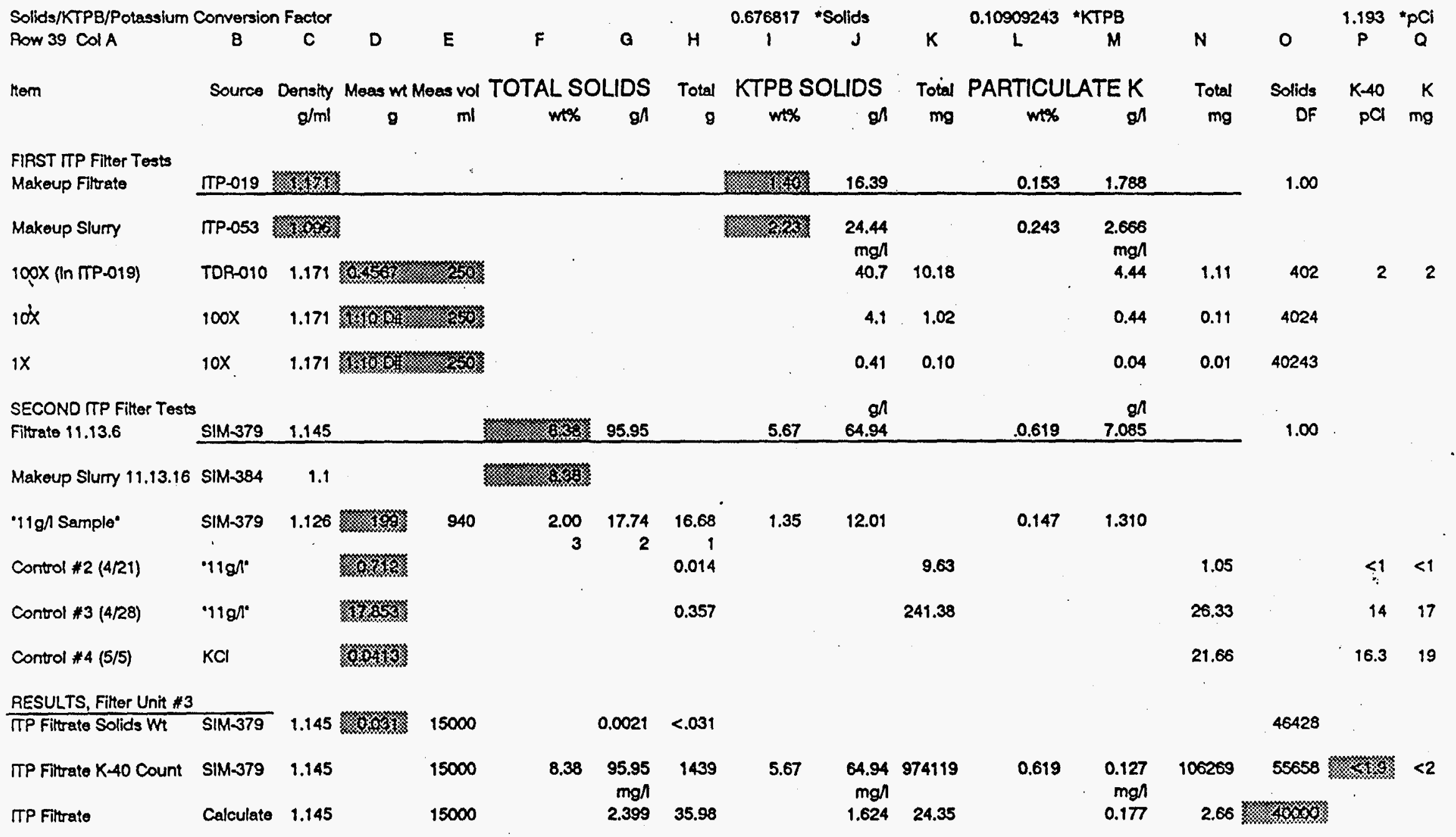

5 